\title{
Using isothermal calorimetry and FT-Raman spectroscopy for step-by-step monitoring of maize seed germination: case study
}

\author{
Iwona Stawoska ${ }^{1}$ (D) $\cdot$ Aleksandra M. Staszak ${ }^{2} \cdot$ Iwona Ciereszko $^{2} \cdot$ Jakub Oliwa $^{3} \cdot$ Andrzej Skoczowski $^{1}$
}

Received: 4 July 2019 / Accepted: 6 March 2020 / Published online: 17 March 2020

(c) The Author(s) 2020

\begin{abstract}
Thermoanalytical methods are widely used to study seed germination processes. Our research aimed to use them in order to monitor the germination of maize seeds. To this end, we employed-for the first time-the isothermal calorimetric method with full oxygen access. Dry seeds were placed in ampoules with threaded caps, filled with distilled water. Heat flow was recorded in microwatts at $20^{\circ} \mathrm{C}$ for $72 \mathrm{~h}$ in order to determine changes in thermal power associated with germination. In parallel with these measurements, in the same time regime, we measured FT-Raman spectra, which allowed us to analyze how endosperm and embryo changed their chemical compositions during imbibition and germination. Spectra obtained for endosperm reflected chemical changes resulting from catabolic processes. We also analyzed variations in the secondary structure of proteins in the embryo accompanying germination. Decomposition of amide I bands proved that during germination and protein hydrolysis, the content of helical and $\beta$-sheet structures decreased. Furthermore, in the embryos of dry seeds, S-S linkages were in both gauche-gauche-trans and trans-gauche-trans conformations, but after imbibition, only gauche-gauche-trans conformation can be identified.
\end{abstract}

Keywords Seed germination $\cdot$ FT-Raman spectroscopy $\cdot$ Decomposition $\cdot$ Secondary structure of proteins $\cdot$ Zea mays

\section{Introduction}

Among the critical stages of plant life is seed germination. It is during this stage that the plant's genetic pool is transferred to the environment, a critical process behind perpetuating the species. Germination ends the plant's quiescent phase, making it metabolically active. To germinate, seeds need to complete the imbibition phase, in which colloids are hydrated, leading to enzymes becoming active and reserves being hydrolyzed. After that period, anabolic processes

Iwona Stawoska and Aleksandra M. Staszak have contributed equally to this work.

Iwona Stawoska

iwona.stawoska@up.krakow.pl

1 Institute of Biology, Pedagogical University of Cracow, Podchorążych 2, 30-084 Kraków, Poland

2 Institute of Biology, University of Bialystok, Ciołkowskiego 1J, 15-245 Białystok, Poland

3 Department of Chemistry and Biochemistry, Institute of Basic Sciences, University of Physical Education, Jana Pawła II 78, 31-571 Krakow, Poland start, and embryo radicle is growing. During reserve mobilization, stored materials are enzymatically decomposed to simpler components, which then serve as energy source for the embryo and forming seedlings. Germination ends when the radicle breaks the seed coat, a moment that marks the formation of a seedling and the beginning of its grow [1].

Isothermal calorimetry is used to monitor many biological processes, such as fermentation [2], microorganism development [3], and seed germination [4-6]. Some authors used it to analyze the physiological quality of seeds stored in various conditions [5] and the influence of chemical [7, 8] and physical [9] factors on germination. Schabes and Sigstad discussed methodological aspects of using calorimetry in studying seed germination [10]. However, the thermal effect of metabolic processes associated with seed germination still requires further research.

FT-Raman spectroscopy can enrich isothermal calorimetry's results, by enabling one to analyze chemical compositions of tissues in a non-destructive manner. To the best of our knowledge, only a few studies have combined calorimetry with FT-Raman spectroscopy. Two of them analyzed changes in the chemical composition of cotyledons at the final stages of germination of mustard seeds and early stages 
of growth of its seedlings [11, 12]. Chemical changes occurring from the imbibition phase to the root protrusion through the seed coat, however, have not yet been studied in detail.

This work aimed to (1) analyze metabolic energy changes related to the subsequent steps of seed germination in maize, using the isothermal calorimetry; and to (2) analyze the chemical composition of endosperm and embryo, using FT-Raman spectroscopy. In the analyses, we paid special attention to variations in the secondary structure of proteins localized in the embryo. We chose maize seeds because they have relatively large and wellvisible embryos, allowing us to precisely aim the laser beam at both endosperm and embryo. To carry out calorimetric measurements, we used ampoules with threaded caps, a novel approach that let us to conduct the long-term experiment under unlimited oxygen access.

\section{Materials and methods}

\section{Plant material}

The experiments used maize seeds (Zea mays L., cv Rywal, FAO 210) obtained from the plant breading station HR Smolice (Poland), which were not prepared in any way. All the experiments were performed in at least five independent series. The details can be found at figures descriptions.

\section{Imbibition and germination studies}

In order to investigate the rate of water uptake by seeds during the first six hours of imbibition, the water content coefficient $\left(\mathrm{WC} / \mathrm{g}_{\mathrm{H} 2 \mathrm{O}} \mathrm{g}_{\mathrm{FM}}^{-1}\right)$ was calculated according to Schabes and Sigstad [5]. In brief, dry seeds were introduced into ventilated calorimetric ampoules with a capacity of $20 \mathrm{~cm}^{3}$, filled with $1 \mathrm{~cm}^{3}$ of distilled water (see "Calorimetric measurements" below). The ampoules were placed in an isothermal calorimeter TAM III (TA Instruments, Lindon, UT) at $20{ }^{\circ} \mathrm{C}$. Such a procedure ensured that the seed imbibitions were carried out at exactly the same temperature; at the same temperature, HF from the seeds was measured.

To illustrate changes in morphology during imbibition, the seeds were removed from the ampoules every $12 \mathrm{~h}$ and photographed (Fig. 1), and then placed back into the calorimeter. The procedure was repeated up to $72 \mathrm{~h}$.

\section{Calorimetric measurements}

Calorimetric measurements were made in an isothermal twin $20 \mathrm{~cm}^{3}$ calorimeter TAM III, equipped with TAM Assistant Software. Stainless-steel ampoules with threaded
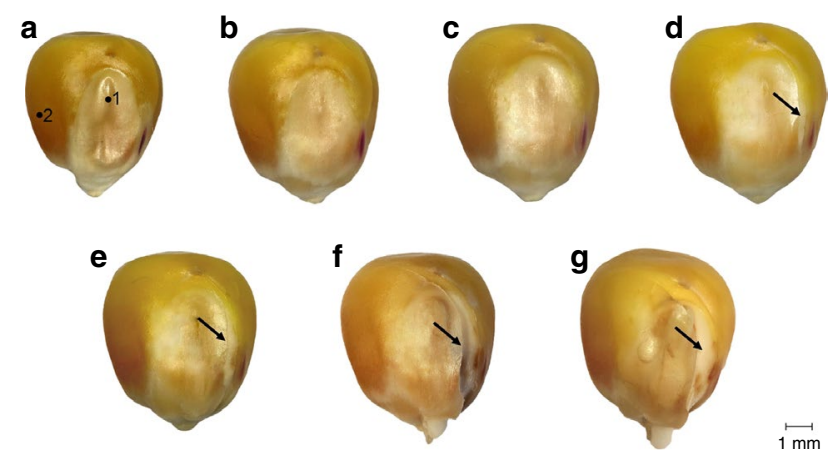

$\stackrel{\longmapsto \mathrm{mm}}{\longmapsto}$

Fig. 1 A maize seed (Zea mays L., cv Rywal, FAO 210) during germination. The photographs were made every $12 \mathrm{~h}$ (from $0 \mathrm{~h}$ (a) to $72 \mathrm{~h}(\mathbf{g})$ ). On seed (a), black points described as 1 (the embryo) and 2 (the endosperm) indicate the places where FT-Raman measurements were made. The differences in the sizes of the seeds on individual photographs resulted from the imbibition and germination processes. The arrows indicate the places of seed coat rupture. Similar qualitative changes were observed for the other three seeds undergoing imbibition and germination under identical conditions

caps, previously manufactured by Thermometric (Järfälla, Sweden) for TAM II 2277 calorimeters, were used. Thanks to them, we did not have to open ampoules to ensure $\mathrm{O}_{2}$ availability.

The particular measurements for an individual seed were made in the following way. The seed was placed in the calorimetric ampoule, filled with $1 \mathrm{~cm}^{3}$ of distilled water; the reference ampoule was also filled with $1 \mathrm{~cm}^{3}$ of distilled water. The HF for germination (in $\mu \mathrm{W}$ ) was registered after the temperature equilibration period (45 min) at $20^{\circ} \mathrm{C}$, allowing us to graph $\mathrm{HF}$ against time. The measurements were made for $72 \mathrm{~h}$. After that time, the seed was lyophilized and weighed, in order to calculate its $\mathrm{HF}$ of germination, expressed as $\mu \mathrm{W}$ per gram of dry mass $\left(\mathrm{g}_{\mathrm{DM}}\right)$.

To study whether and how the ampoules with threaded caps influenced the calorimetric signal value, we made separate measurements using both ampoules filled with $1 \mathrm{~cm}^{3}$ of distilled water. This experiment aimed to study the thermal effect that occurs when water evaporates from ampoules with threaded caps.

\section{FT-Raman spectroscopy and curve fitting}

FT-Raman spectroscopy was performed with the Nicolet NXR 9650 FT-Raman spectrometer equipped with a Nd:YAG3 + laser emitting at $1064 \mathrm{~nm}$ and InGaAs (indium gallium arsenide), on maize seeds prepared as described above ("Imbibition studies"), onto two points indicated on Fig. 1a. Spectra were collected from the beginning of imbibition until root appearance-so, after 0 (air-dry seeds), 6, 18, 24, 36, and $60 \mathrm{~h}$-at room 
temperature, at an aperture of 80 and a spectral resolution of $4 \mathrm{~cm}^{-1}$. From 7 to 10 , single spectra accumulated from 64 scans and measured with the laser power of $1 \mathrm{~W}$ were collected in the range of $300-1800 \mathrm{~cm}^{-1}$ and averaged. The spectra were normalized according to the most intensive band, and the analysis was carried out using Omnic 8 and OriginPro 2015 software packages for Windows.

To determine the secondary structural content of proteins localized in maize embryos in the subsequent steps of germination, the amide I $\left(1610-1710 \mathrm{~cm}^{-1}\right)$ band was decomposed using the PeakFit 4.12 program [13]. The analysis started with a baseline correction that used a linear function. In the next step, a second derivative of each measured spectrum was obtained, in order to find the number of components that built an amid I as well as their localization. Finally, we used a mathematical algorithm, employing Gaussian and Lorentzian functions, to iteratively estimate parameters using the method of least squares. In this method, the areas of selected peaks correspond to their conformational contributions. The iteration procedure stops when it achieves the best fit-one that cannot be improved anymore. For each obtained decomposition, the correlation coefficient was higher than 0.998 .

\section{Results and discussion}

Our research used calorimetric measurements combined with FT-Raman spectroscopic experiments to monitor seed germination of maize cultivar Rywal, in its early stages, from imbibition to root protrusion. We monitored this process for $60 \mathrm{~h}$ using FT-Raman spectroscopy and $72 \mathrm{~h}$ using calorimetry.

Seed coats broke at around $36 \mathrm{~h}$ of imbibition (Fig. 1d, e). Root protrusion through the seed coat-which indicates that the germination ended-became clearly visible after $60 \mathrm{~h}$ (Fig. 1f). The epicotyl appeared after $72 \mathrm{~h}$ since the beginning of imbibition (Fig. 1g).

One of the main problems in biological calorimetry is the small amount of oxygen in measuring ampoules, which makes it difficult-often even impossible-to follow metabolic heat flow over a longer period of time. To solve this problem, some authors interrupted the measurements after 9-10 $\mathrm{h}[8]$ or $10-12 \mathrm{~h}[5,6,10]$ and opened the ampoules to let oxygen get inside. While indeed increasing the amount of oxygen in the ampoules, the procedure does not come without cost: It causes disturbances in HF measurements. According to our experience and knowledge, such an interruption makes a calorimetric signal time-consuming-or just difficult - to stabilize. Therefore, we proposed to use ampoules with threaded caps in current studies. As Fig. 2, Inset shows, the calorimetric signal-that is, the one originating from ampules with threaded caps filled only with $1 \mathrm{~cm}^{3}$ of distilled water-varied from 0 to $4 \mu \mathrm{W}$ within the first $12 \mathrm{~h}$ of measurement and then stabilized, not exceeding $5 \mu \mathrm{W}$. Thus, for the obtained HF curve for the germination of maize seeds (Fig. 2), the inaccuracy of the signal value did not exceed 5\%, meaning that using ampoules with threaded caps, which offered the seeds favorable oxygen conditions, allowed us to monitor the undisturbed processes of their imbibition and germination. Thus, our measurements remained unaffected by a lack of oxygen.

For imbibition processes lasting less than $10 \mathrm{~h}$, the corresponding $\mathrm{HF}$ value decreases (Figs. 2, 3a). In turn, variations in HF detected at around $1.7 \mathrm{~h}$ after the beginning of imbibition in our opinion reflect the effect of mechanical tension the seeds underwent during the first stages of imbibition (Fig. 1, arrow no. 1). Similar changes in HF observed in soybeans seeds [10] were explained by anoxia. We do not think, however, that at this stage of imbibition, anoxia-if occurs whatsoever-influences metabolic activity, which would be seen in the changes in the HF curve.

Between 10 and around $40 \mathrm{~h}$, metabolic activity intensified, as represented by an increasing metabolic heat rate. Moreover, after about $40 \mathrm{~h}$, we can see a rapid increase in HF (Fig. 2, arrow no. 2), a pattern associated with the rupture of the seed coat (Fig. 1d) and the resulting acceleration of the metabolic processes. After about $53 \mathrm{~h}$, root protrusion through the seed coat became visible (Fig. 2, arrow no. 3, Fig. 1f), but it did not disturb the constant increase in the

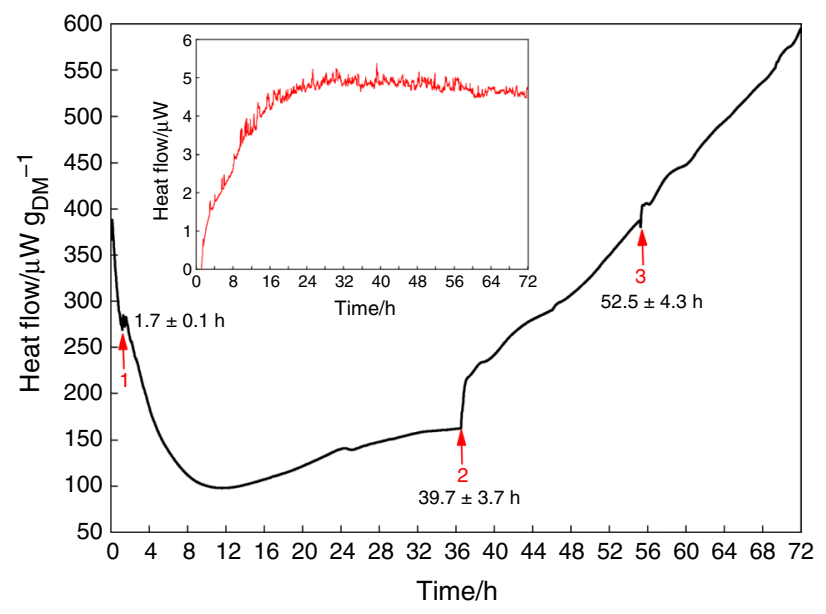

Fig. 2 A typical specific heat flow (HF) curve in microwatts $(\mu \mathrm{W})$ per gram of dry mass $\left(\mathrm{g}_{\mathrm{DM}}\right)$ for a maize seed germinating at $20{ }^{\circ} \mathrm{C}$ in $1 \mathrm{~cm}^{3}$ of distillated water. Arrow 1 points to imbibition-related mechanical tension inside the seed. Arrows 2 and 3 show the disruption of the seed coat. Inset: The calorimetric signal obtained for the ventilated ampoules filled with $1 \mathrm{~cm}^{3}$ of distillated water. The numerical values (the mean time in hours from the beginning of germination, with standard deviation) show when mechanical stress, seed coat cracking, and root protrusion took place. $\mathrm{N}=5$ 
HF value that started with the breaking of the seed coat (at around $40 \mathrm{~h}$ ).

Figure 3 shows that during the first $6 \mathrm{~h}$ of imbibition, around $92 \%$ of variation in HF can be explained by the changes in the water content in seeds (WC). In other words, the HF signal during imbibition is directly related to the amount of water absorbed by the seed.

To evaluate chemical changes during the initial stages of germination, we used FT-Raman spectrometry to collect signals from two points of seed coats: the embryo (point 1) and endosperm (point 2) (Fig. 1a). This technique enables one to measure spectra without disturbing the integrity of the seeds.

The main component of maize seed's endosperm is starch (86.4-88.9\% of total mass). It consists of two polymers: amylopectin (70-75\%) and amylose (25-30\%), whose amount in the embryo is much smaller $(5.1-10.0 \%$ of the embryos' mass). Maize seed also contains sugars, including
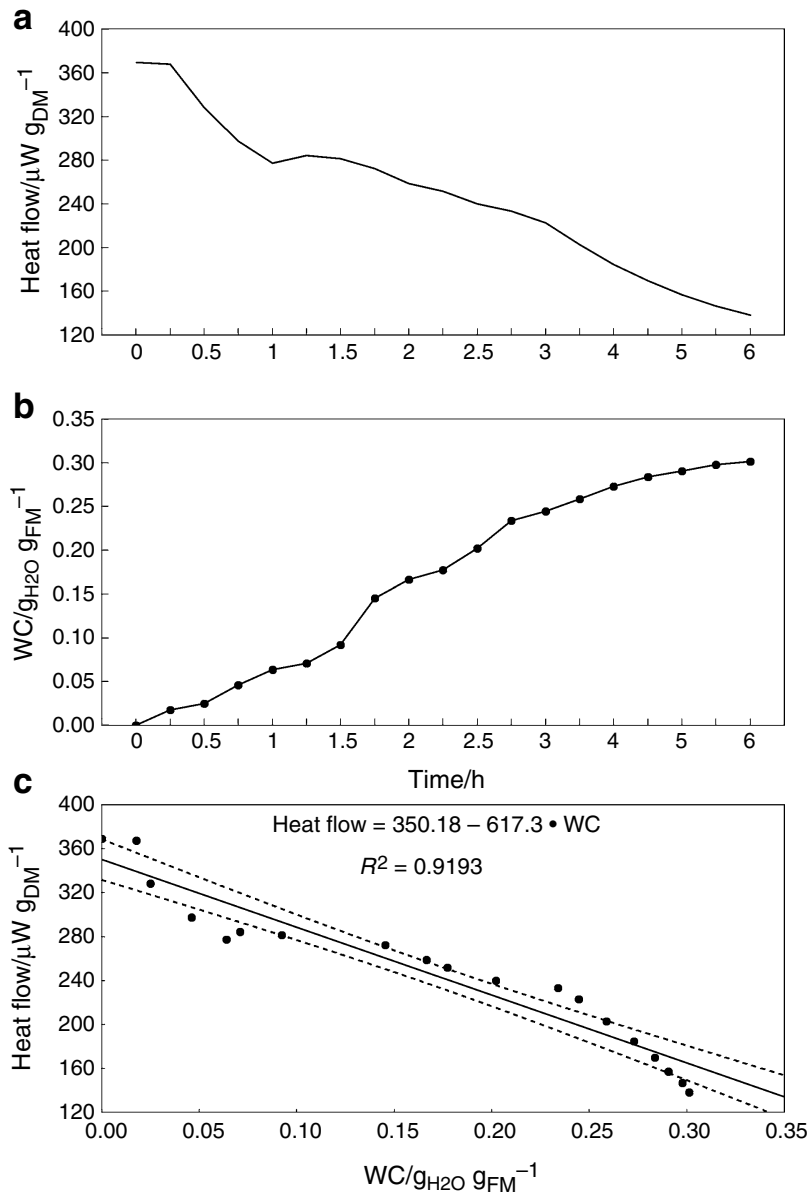

Fig. 3 Specific heat flow (HF) in microwatts $(\mu \mathrm{W})$ per gram of dry mass $\left(\mathrm{g}_{\mathrm{DM}}\right)$ during imbibition $(\mathbf{a})$; the imbibition curve of maize seeds during the first six hours: the mean water content (WC) in gram of water $\left(\mathrm{g}_{\mathrm{H} 2 \mathrm{O}}\right)$ per gram of fresh mass $\left(\mathrm{g}_{\mathrm{FM}}\right) . N=6$, and the maximum standard deviation was below $5 \%$, so is not shown (b); correlation between specific HF and water content (WC) in the seeds. The dashed lines show $95 \%$ confidence intervals (c) pentosans. Additionally, seeds contain lipids (whose mean percentage in the seed's mass is $4.4 \%$ ), mainly stored in embryos (31.1-35.1\% of its total chemical composition). In turn, protein content in maize seeds ranges from 8.1 to $11.5 \%$, with the embryo being their main localization, proteins constituting up to $19 \%$ of its total composition [14].

Figure $4 \mathrm{a}$ and $4 \mathrm{~b}$ shows Raman vibration characteristic for the above-mentioned chemical groups recorded in the endosperm and embryo. Table 1 summarizes these results.

Intensive bands observed in the $475-485 \mathrm{~cm}^{-1}$ range and the one at $940 \mathrm{~cm}^{-1}$ are typical of starch, so they allowing one to identify it in various samples [15, 16]. Analyzing of spectra in terms of the intensity and changes in position of these bands, it is possible to study amylose and amylopectin contents [16]. The following Raman vibrations existing in glycosidic bond occur between 800 and $1200 \mathrm{~cm}^{-1}$ : $\mathrm{C}-\mathrm{O}$ stretching, $\mathrm{C}-\mathrm{C}$ stretching, and $\mathrm{C}-\mathrm{O}-\mathrm{C}$ deformation
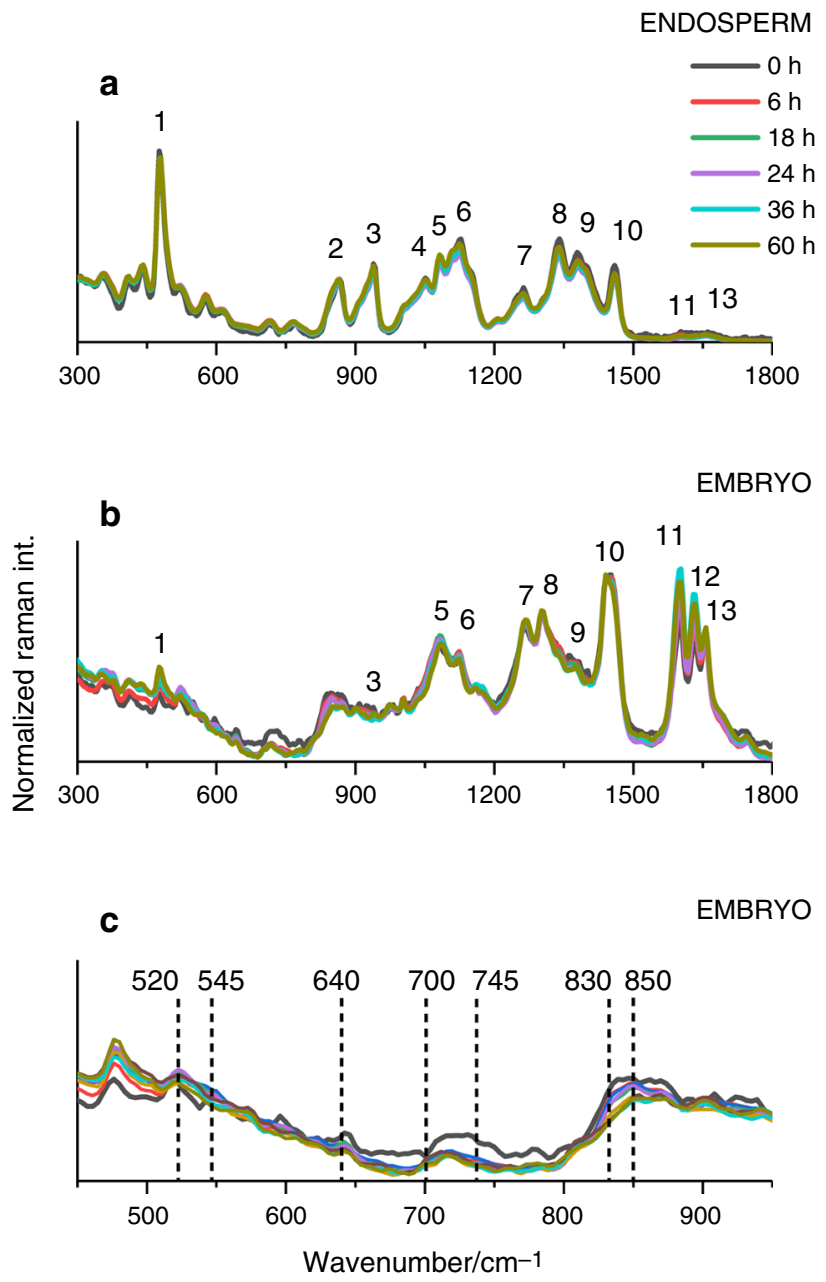

Fig. 4 The normalized FT-Raman spectra of maize seeds (Zea mays L., cv Rywal): the endosperm (a); the embryo of the seed (b, c). The spectra were measured at $0,6,18,24,36$, and $60 \mathrm{~h}$ from the beginning of germination. Numbers 1-13 indicate various chemical compounds present in the maize seeds 
Table 1 The most characteristic Raman bands obtained for the maize seeds studied

\begin{tabular}{llll}
\hline Peak number & Wavenumber $/ \mathrm{cm}^{-1}$ & Chemical components & References \\
\hline $\mathbf{1}$ & $\mathbf{4 8 0}$ & $\begin{array}{l}\text { Polysaccharides (amylose and amylopectin) } \\
\text { Monosaccharides, disaccharides, polysaccha- } \\
\text { rides (amylose and amylopectin) }\end{array}$ & {$[15,21,38-41]$} \\
$\mathbf{3}$ & $\sim 865$ & Polysaccharides (amylose and amylopectin) & {$[15,21,39]$} \\
4 & $\mathbf{9 4 0}$ & Polysaccharides & {$[40,41]$} \\
5 & 1052 & Polysaccharides & {$[21]$} \\
6 & 1082 & Polysaccharides (amylose and amylopectin) & {$[15,21,40]$} \\
7,8 & 1128 & Polysaccharides, lipids, fatty acids & {$[15,16,21,40]$} \\
9 & $1260-1340$ & Polysaccharides & {$[15,16,21,39]$} \\
10 & 1380 & Polysaccharides, lipids, fatty acids & {$[15,16,21,42,43]$} \\
11 & 1460 & Polyphenols, flavonoids & {$[39,44]$} \\
12 & 1600 & HW & {$[28]$} \\
13 & 1630 & Amid I & {$[39]$} \\
\hline
\end{tabular}

Bold font shows "marker bands" of particular chemical components modes. Vibrations derived from $\alpha-1,4$-glycosidic connections were observed in the range of $920-960 \mathrm{~cm}^{-1}$. Thus, the peak at $940 \mathrm{~cm}^{-1}$ is associated mainly with the presence of $\alpha-1,4$-glycosidic bonds characteristic for amylose, or $\alpha-1,6$-glycosidic, characteristic for amylopectin. The presence of $\alpha-1,6$-glycosidic bonds causes a slight shift of the band toward higher frequencies. To determine which type of bonds prevails in the examined tissue, the spectra of pure compounds should be recorded and compared with those obtained for tested sample. The region between 1200 and $1500 \mathrm{~cm}^{-1}$ is rich in structural information about carbohydrates, being thus characteristic, among others, for $\mathrm{C}-\mathrm{H}$, $\mathrm{CH}_{2}, \mathrm{C}-\mathrm{O}-\mathrm{H}$ deformation vibrations at $1460 \mathrm{~cm}^{-1}[16,17]$. At a frequency of about $1380 \mathrm{~cm}^{-1}$, coupling the $\mathrm{C}-\mathrm{C}-\mathrm{H}$ and $\mathrm{C}-\mathrm{O}-\mathrm{H}$ deformation modes can be observed.

We observed the highest signal values in the endosperm for dry seeds between 1100 and $1500 \mathrm{~cm}^{-1}$ (Fig. 4a). The same tendency occurred in the amide I region, although with low intensity. After an imbibition and further changes related to germination, the intensity of the signal decreased in the above-mentioned ranges, a phenomenon connected with the triggering of catabolic processes starting germination, mainly the breaking down of carbohydrates and proteins. These differences in the intensities of signals, especially between 6 and $60 \mathrm{~h}$ of germination, are, however, negligible. In the endosperm, marker bands for starch were clearly visible, with band 1 located at $480 \mathrm{~cm}^{-1}$ and band 2 at $940 \mathrm{~cm}^{-1}$, an observation in agreement with the common knowledge about the main storage material accumulated therein. [14].

The embryos of dry seeds and those after imbibition differed in terms of the signal intensity of the FT-Raman spectra up to $550 \mathrm{~cm}^{-1}$ and in the region of $550-1000 \mathrm{~cm}^{-1}$ (Fig. $4 \mathrm{~b})$. In the low frequency range $\left(510-550 \mathrm{~cm}^{-1}\right)$, the identified bands were associated with S-S stretching vibrations (Fig. 4c). The major storage proteins in maize kernels are zeins, which are composed of four classes, namely $\alpha-$, $\beta-, \gamma-$, and $\delta$-zeins, of which $\alpha$-zeins are sulfur-deficient, $\beta$ - and $\delta$-zeins are sulfur-rich and have high concentrations of cysteine and methionine, and $\gamma$-zeins are cysteine-rich [18]. The bands at 510, 520, and $545 \mathrm{~cm}^{-1}$ are known to be typical for gauche-gauche-gauche, gauche-gauche-trans, and trans-gauche-trans conformations of the C-C-S-S-C-C sequence, respectively. From among the spectra we observed in our experiment, the band at $520 \mathrm{~cm}^{-1}$ was present during the whole germination process, but the band at $545 \mathrm{~cm}^{-1}$ disappeared just after imbibition Therefore, we can conclude that the S-S linkages of dry seeds were in gauche-gauchetrans and trans-gauche-trans conformations, but imbibition changed that, with only the former left. Moreover, the bands at $640 \mathrm{~cm}^{-1}$ and in the $700-745 \mathrm{~cm}^{-1}$ region were assigned to the C-S stretching vibrations of gauche and trans conformations, respectively [19]. The peaks at 850 and $830 \mathrm{~cm}^{-1}$ were assigned to tyrosine residues (Fig. 4c), with the $\mathrm{I}_{850} /$ $\mathrm{I}_{830}$ ratio being used as an indicator of the tyrosine environment [20]. From our results it follows that for dry seeds, the hydroxyl group of tyrosine is a donor of rather strong hydrogen bonds (as represented by a lower value of $\mathrm{I}_{850} / \mathrm{I}_{830}$ ), whereas in the later stages of germination, it is an acceptor of hydrogen bonds.

The marker band for starch shifted from $940 \mathrm{~cm}^{-1}$ for the endosperm to lower frequencies (ca. $930 \mathrm{~cm}^{-1}$ ) for the embryo, along with a significant decrease in the band's intensity (Fig. 4b, peak no. 3). This may suggest the absence-or at least a low contents-of $\alpha-1,6$-glycosidic linkages as well as the presence of the majority of $\alpha-1,4$-glycosidic bonds in these structures of the embryo [21].

At $1656 \mathrm{~cm}^{-1}$, we can see a peak derived from the amide I band, a typical feature of the embryo (Fig. 4b). Vast literature has shown that the mobilization of storage substances in seeds starts the process of degradation of proteins deposited in the aleurone layer that surrounds the endosperm. Then, 
de novo hydrolases are synthesized (in both aleurone layer and embryo). In the next stage, hydrolases that are released into the starch's endosperm participate in the degradation of polysaccharides and proteins, with the resulting products being transported to the developing seedling [22, 23].

Created by the vibrations of the peptide bond, the amide I allows one to determine the secondary structures of proteins [24]. Using literature data [13, 25-27] and the second derivative functions of the recorded spectra, we distinguished three components of amid I: $\alpha$-helix, located at $1656 \mathrm{~cm}^{-1} ; \beta$-sheets, at $1673 \mathrm{~cm}^{-1}$; and undefined structures, at $1691 \mathrm{~cm}^{-1}$. The decomposition of the recorded spectra revealed the presence of additional bands, positioned at 1628 and $1635 \mathrm{~cm}^{-1}$, assigned to hydration water [28]. We estimated the maximum difference of the frequency of the components between the registered spectra as $\pm 2 \mathrm{~cm}^{-1}$. The halfwidth of the components was not wider than $15-20 \mathrm{~cm}^{-1}$. To determine the secondary structure content, we used the area of each of the components divided by the sum of area of all the amide I components. Figure 5 presents the example of such decompositions, for spectra obtained at the starting point ( $0 \mathrm{~h}$, air-dry seed), at the end of imbibition $(6 \mathrm{~h})$, and at the end of germination (a root protrusion, $60 \mathrm{~h}$ ). Table 2 shows the shares of secondary structures obtained from the amide I decomposition during all the germination stages considered.

Our results clearly indicate that proteins in the embryo are predominantly $\alpha$-helical, a conclusion being in agreement with literature [29]. The most abundant proteins in maize are zeins, belonging to prolamin proteins, and are divided into four classes, $\alpha, \beta, \gamma$, and $\delta$-zeins [30]. They have highly ordered structure $[18,30]$ and are composed of up to $60 \% \alpha$-helical forms [29]. Their glutamine and proline contents are high—up to $70 \%$ in total [31], but they have almost no tryptophan and lysine in their chains. As already mentioned, the contents of amino acids, such as cysteine and methionine, depend on the type of zein (unlike other zeins, $\alpha$-zeins have very low contents of sulfur amino acids). Davy et al. showed [32] that the rate of hydrolysis of storage proteins during germination also depended on the reduction of disulfide bonds in proteins.

The decomposition of the spectra recorded for air-dry seeds $(0 \mathrm{~h})$ yielded the amide I band region $\left(1610-1710 \mathrm{~cm}^{-1}\right)$ consisting mainly of $\alpha$-helix (54\%), with only $5 \%$ of $\beta$-sheets and $4 \%$ of undefined structures (Table 1). During imbibition, the helical structures declined up to $47 \%$ and then up to $40 \%$ in $36 \mathrm{~h}$. After $60 \mathrm{~h}$ of germination, the content of helical protein structures increased again, indicating the synthesis of proteins with this type of secondary structure, which might be important during seedling development. During imbibition, the content of $\beta$-sheets declined from 5\% for air-dry seeds to $2 \%$ after $24 \mathrm{~h}$, finally disappearing after $36 \mathrm{~h}$. Undefined structures' content

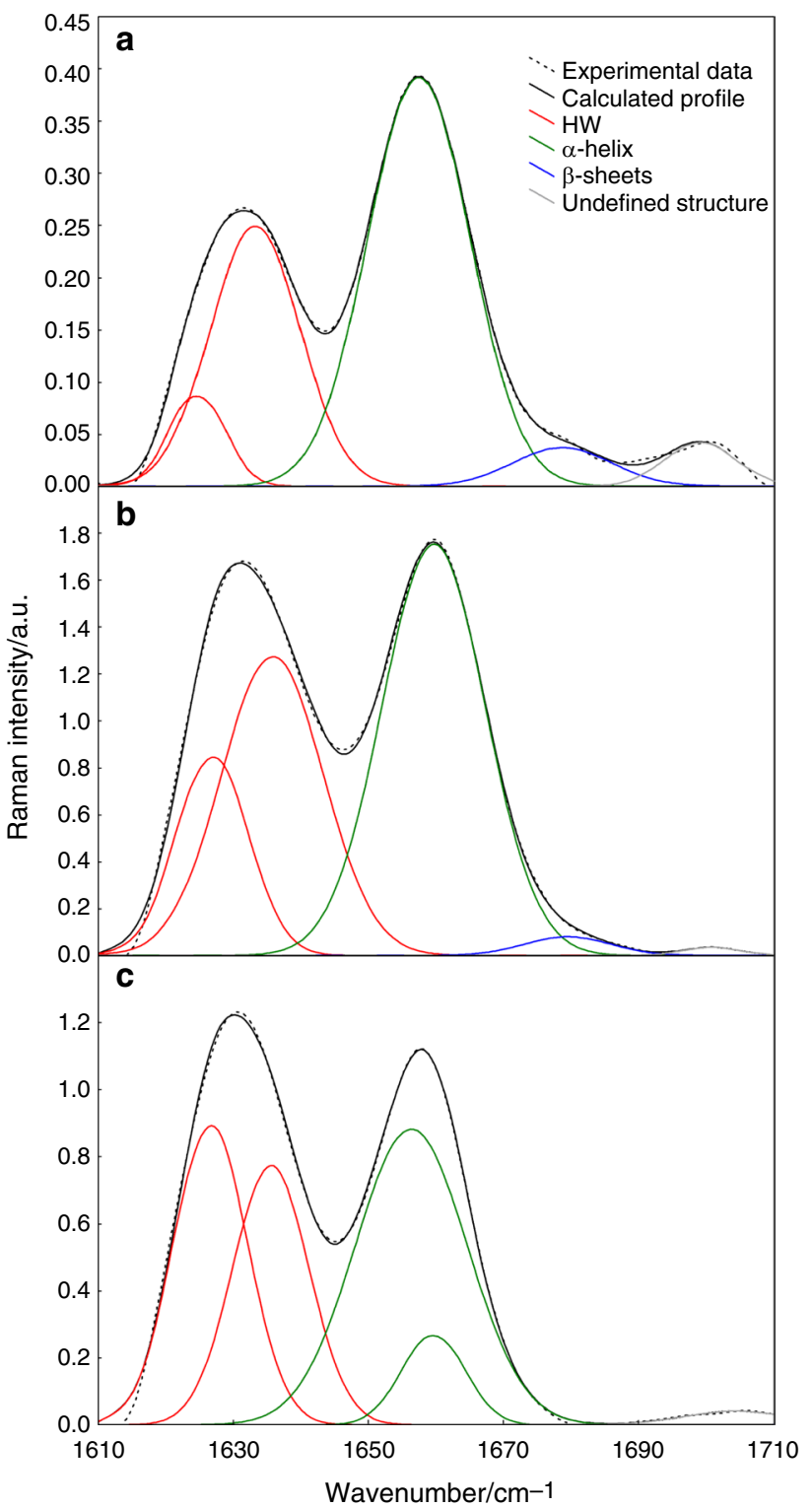

Fig. 5 The decomposition of the FT-Raman amide I region for the embryo. The experimental profiles are represented by dashed black lines and the calculated ones by solid black lines. The calculated profiles in the panels were determined as the sums of the individual curve-fit components, namely $\alpha$-helical (1656-1658 $\mathrm{cm}^{-1}$-green), $\beta$-sheet (1673 $\mathrm{cm}^{-1}$-blue), undefined $\left(1693 \mathrm{~cm}^{-1}\right.$-gray), and hydrated water (HW, $1628 \mathrm{~cm}^{-1}, 1636 \mathrm{~cm}^{-1}$-red) structures. The spectra were measured after 0 (a), 6 (b), and 60 (c) hours from the beginning of the experiment. (Color figure online)

decreased in the imbibition phase (after $6 \mathrm{~h}$ ), completely disappearing between 18 and $36 \mathrm{~h}$ of germination and reappearing after $36 \mathrm{~h}$. We also noted an increase in hydration water (from initial $37 \%$ to above $50 \%$ in the next stages of germination).

Note the peaks located at $1628 \mathrm{~cm}^{-1}$ and $1636 \mathrm{~cm}^{-1}$, which we described as "hydration water." We can identify in this frequency range vibrations derived from aromatic 
Table 2 The estimated content of protein secondary structures in the embryo of maize seeds (Zea mays L., cv Rywal) in air-dry seeds $(0 \mathrm{~h})$ and during the first $60 \mathrm{~h}$ of germination

\begin{tabular}{llllll}
\hline \multirow{2}{*}{ Time/h } & \multicolumn{3}{l}{$\begin{array}{l}\text { Type of conformation and secondary structure } \\
\text { content/\% }\end{array}$} & $R^{2}$ \\
\cline { 2 - 5 } & HW & $\alpha$-helix & $\beta$-sheet & Undefined & \\
\hline 0 & $7^{*}$ & 54 & 5 & 4 & 0.9992 \\
& $30^{* *}$ & & & & \\
6 & $16^{*}$ & 47 & 2 & 1 & 0.9991 \\
& $34^{* *}$ & & & & \\
18 & $15^{*}$ & 46 & 1 & - & 0.9989 \\
24 & $\begin{array}{l}38^{* *} \\
10^{*}\end{array}$ & 45 & 2 & - & 0.9981 \\
36 & $43^{* *}$ & & & & 0.9986 \\
60 & $15^{*}$ & 40 & - & 2 & 0.9989 \\
& $44^{* *}$ & & & & \\
\hline
\end{tabular}

*Content determined at $1628 \mathrm{~cm}^{-1}$

$* *$ Content determined at $1636 \mathrm{~cm}^{-1}$

*** Content determined at $1656 \mathrm{~cm}^{-1}$ and $1658 \mathrm{~cm}^{-1}$

amino acids, like tryptophan and phenylalanine [33]. But since about $60 \%$ of proteins in maize seeds are zeins, which are poor in both lysine and aromatic amino acids [14], assigning these frequencies to these chemical compounds would be inappropriate. Some authors have thus suggested that these peaks can be assigned to the amide groups involved in extended $\beta$-sheets or $\beta$-sheets with strong hydrogen bonding [27, 34-37]. This interpretation, however, may indicate the prevalence of $\beta$-structures in the embryo's proteins, something that is, at most, unlikely. Therefore, given that the molecules were in the solid state, the most appropriate conclusion seems to be assigning the bands at the frequencies of $1628 \mathrm{~cm}^{-1}$ and $1636 \mathrm{~cm}^{-1}$ to the hydration water bending mode $[24,28]$.

Changes in the protein composition of seeds are typically examined during germination. To the best of our knowledge, this experiment was the first to monitor changes in the secondary structure of proteins during embryo growth. To this end, we used FT-Raman spectroscopy, since obtaining the same information using other techniques (e.g., CD or crystallography) would require expensive and time-consuming research.

\section{Conclusions}

We based our idea behind this research on the notion that isothermal calorimetry can be useful in studying the course of germination of various seed species. It indeed showed this usefulness for maize.

The traditional approach in calorimetry uses ampoules without oxygen access, making experiments with germinating seeds lack one of the crucial factors for seeds to germinate: oxygen. Opening the ampoules solves the problem, since oxygen gets into them, but it is just an inefficient half-measure. Solving this problem, it generates other issue, related to the stability of the calorimetric signal. This is where calorimetric ampoules with threaded caps show their power: Unlike traditional ampoules, they let the air inside. Thanks to this, we can continuously monitor HF values during germination. Such a measuring system requires that HF from the plant tissue be much higher than that from ampoules with water-and, unlike traditional calorimetry, the method we used does meet this requirement.

FT-Raman spectroscopy enabled us to notice changes in the secondary structure of proteins in the embryo accompanying the germination process, which we would not be able to monitor in such an easy manner using other techniques. The decomposition of amide I band reveals changes in the proportions of secondary structures of proteins at particular stages of germination. In the embryos of air-dry seeds, S-S linkages were in both gauche-gauche-trans and transgauche-trans conformations, but after imbibition, the latter disappeared and only the former remained.

Acknowledgements Isothermal calorimetric measurements were performed in the Isothermal Calorimetry Laboratory belonging to The Franciszek Górski Institute of Plant Physiology, Polish Academy of Science, Kraków, Poland.

Open Access This article is licensed under a Creative Commons Attribution 4.0 International License, which permits use, sharing, adaptation, distribution and reproduction in any medium or format, as long as you give appropriate credit to the original author(s) and the source, provide a link to the Creative Commons licence, and indicate if changes were made. The images or other third party material in this article are included in the article's Creative Commons licence, unless indicated otherwise in a credit line to the material. If material is not included in the article's Creative Commons licence and your intended use is not permitted by statutory regulation or exceeds the permitted use, you will need to obtain permission directly from the copyright holder. To view a copy of this licence, visit http://creativecommons.org/licenses/by/4.0/. 


\section{References}

1. Becraft PW. Aleurone cell development. In: Olsen O-A, editor. Endosperm. Developmental and molecular biology. Plant cell monographs. Berlin: Springer; 2007. p. 45-56.

2. Morozova K, Armani M, Scampicchio M. Isothermal calorimetry for monitoring of grape juice fermentation with yeasts immobilized on nylon-6 nanofibrous membranes. J Therm Anal Calorim. 2020;139(1):375-82.

3. Fessas D, Schiraldi A. Isothermal calorimetry and microbial growth: beyond modeling. J Therm Anal Calorim. 2017;130(1):567-72.

4. Skoczowski A, Troć M. Isothermal calorimetry and Raman spectroscopy to study response of plants to abiotic and biotic stresses. In: Rout GR, Das AB, editors. Molecular stress physiology of plants. New York: Springer; 2013. p. 263-88.

5. Schabes FI, Sigstad EE. Is it possible to determine physiological quality and best conditions of storage of soybean seeds by isothermal calorimetry? Thermochim Acta. 2014;579:45-9.

6. Schabes FI, Sigstad EE. Monitoring soybean seed germination by calorimetry. J Therm Anal Calorim. 2011;104(1):5-11.

7. Schabes FI, Sigstad EE. Calorimetric studies of quinoa (Chenopodium quinoa Willd.) seed germination under saline stress conditions. Thermochim Acta. 2005;428(1-2):71-5.

8. Schabes FI, Sigstad EE. A calorimetric study of the allelopathic effect of cnicin isolated from Centaurea diffusa Lam. on the germination of soybean (Glicine max) and radish (Raphanus sativus). Thermochim Acta. 2007;458(1-2):84-7.

9. Dymek K, Dejmek P, Panarese V, et al. Effect of pulsed electric field on the germination of barley seeds. LWT-Food Sci Technol. 2012;47(1):161-6.

10. Schabes FI, Sigstad EE. Optimizing conditions to study seed germination by calorimetry using soybean (Glycine max L. Merr.) seeds. Thermochim Acta. 2006;450(1-2):96-101.

11. Troc M, Skoczowski A, Baranska M. The influence of sunflower and mustard leaf extracts on the germination of mustard seeds. J Therm Anal Calorim. 2009;95(3):727-30

12. Skoczowski A, Troć M, Baran A, Baranska M. Impact of sunflower and mustard leaves extracts on the growth and dark respiration of mustard seedlings. J Therm Anal Calorim. 2011;104(1):187-92.

13. Stawoska I, Weselucha-Birczynska A, Regonesi ME, Riva M, Tortora P, Stochel G. Interaction of selected divalent metal ions with human ataxin-3 Q36. J Biol Inorg Chem. 2009;14(8):1175-85.

14. Watson SA. Description, development, structure, and composition of the corn kernel. In: White PJ, Johnson LA, editors. Corn: chemistry and technology 2ed. St Paul: USA American Association of Cereal Chemists; 2003. p. 69-106.

15. Kizil R, Irudayaraj J, Seetharaman K. Characterization of irradiated starches by using FT-Raman and FTIR spectroscopy. J Agric Food Chem. 2002;50(14):3912-8.

16. Almeida MR, Alves RS, Nascimbem L, Stephani R, Poppi RJ, de Oliveira LFC. Determination of amylose content in starch using Raman spectroscopy and multivariate calibration analysis. Anal Bioanal Chem. 2010;397(7):2693-701.

17. Mahdad-Benzerdjeb A, Taleb-Mokhtari IN, Sekkal-Rahal M. Normal coordinates analyses of disaccharides constituted by D-glucose, D-galactose and D-fructose units. Spectroc Acta Pt A-Molec Biomolec Spectr. 2007;68(2):284-99.

18. Kumamarum T, Ogawa M, Satoh H, Okita TW. Protein body biogenesis in cereal endosperms. In: Olsen OA, editor. Endosperm. Plant cell monographs. Berlin: Springer; 2007. p. 141-58.

19. LiChan ECY. The applications of Raman spectroscopy in food science. Trends Food Sci Technol. 1996;7(11):361-70.

20. Bihan TL, Blochet JE, Desormeaux A, Marion D, Pezolet M. Determination of the secondary structure and conformation of puroindolines by infrared and Raman spectroscopy. Biochemistry. 1996;35(39):12712-22.

21. Liu YQ, Xu Y, Yan YZ, Hu DD, Yang LZ, Shen RL. Application of Raman spectroscopy in structure analysis and crystallinity calculation of corn starch. Starch-Starke. 2015;67(7-8):612-9.

22. Simpson DJ. Proteolytic degradation of cereal prolamins-the problem with proline. Plant Sci. 2001;161(5):825-38.

23. Muntz K, Belozersky MA, Dunaevsky YE, Schlereth A, Tiedemann J. Stored proteinases and the initiation of storage protein mobilization in seeds during germination and seedling growth. $\mathrm{J}$ Exp Bot. 2001;52(362):1741-52.

24. Tu AT. Raman spectroscopy in biology: principles and applications. New York: Wiley; 1982.

25. Chow MKM, Ellisdon AM, Cabrita LD, Bottomley SP. Polyglutamine expansion in ataxin-3 does not affect protein stability-implications for misfolding and disease. J Biol Chem. 2004;279(46):47643-51.

26. Tuma R. Raman spectroscopy of proteins: from peptides to large assemblies. J Raman Spectrosc. 2005;36(4):307-19.

27. Nawrocka A, Mis A, Szymanska-Chargot M. Characteristics of relationships between structure of gluten proteins and dough rheology - influence of dietary fibres studied by FT-Raman spectroscopy. Food Biophys. 2016;11(1):81-90.

28. Debelle L, Alix AJP, Jacob MP, et al. Bovine elastin and kappaelastin secondary structure determination by optical spectroscopies. J Biol Chem. 1995;270(44):26099-103.

29. Lawton JW, Wilson CM. Proteins of the kernel. In: White PJ, Johnson LA, editors. Corn: chemistry and technology. St Paul: American Association of Cereal Chemists; 2003. p. 313-54.

30. Coleman CE, Larkins BA. The prolamins of maize. In: Shewry PR, Casey R, editors. Seed Proteins. Springer: Dordrecht; 1999. p. 109-39.

31. Shewry PR, Halford NG. Cereal seed storage proteins: structures, properties and role in grain utilization. J Exp Bot. 2002;53(370):947-58.

32. Davy A, Sorensen MB, Svendsen I, Cameron-Mills V, Simpson DJ. Prediction of protein cleavage sites by the barley cysteine endoproteases EP-A and EP-B based on the kinetics of synthetic peptide hydrolysis. Plant Physiol. 2000;122(1):137-45.

33. Aslanian D, Grof P, Renault F, Masson P. Raman-spectroscopic study of conjugates of butyrylcholinesterase with organophosphates. Biochim Biophys Acta-Protein Struct Molec Enzym. 1995;1249(1):37-44.

34. Clark AH, Saunderson DHP, Suggett A. Infrared and laser-Raman spectroscopic studies of thermally-induced globular protein gels. Int J Pept Protein Res. 1981;17(3):353-64.

35. Arrondo JLR, Young NM, Mantsch HH. The solution structure of concanavalin-a probed by FT_IR spectroscopy. Biochim Biophys Acta. 1988;952(3):261-8.

36. Subirade M, Gueguen J, Pezolet M. Conformational-changes upon dissociation of a globular protein from pea-a Fourier-Transform Infrared-spectroscopy study. Biochim Biophys Acta-Protein Struct Molec Enzym. 1994;1205(2):239-47.

37. Sivam AS, Sun-Waterhouse D, Perera CO, Waterhouse GIN. Application of FT-IR and Raman spectroscopy for the study of biopolymers in breads fortified with fibre and polyphenols. Food Res Int. 2013;50(2):574-85.

38. Corbett EC, Zichy V, Goral J, Passingham C. Fourier transform Raman studies of materials and compounds of biological importance-II. The effect of moisture on the molecular structure of the alpha and beta anomers of D-glucose. Spectrochim Acta A. 1991;47(9-10):1399-411.

39. Schulz H, Baranska M. Identification and quantification of valuable plant substances by IR and Raman spectroscopy. Vib Spectrosc. 2007;43:13-25. 
40. Wiercigroch E, Szafraniec E, Czamara K, et al. Raman and infrared spectroscopy of carbohydrates: a review. Spectroc Acta Pt A-Molec Biomolec Spectr. 2017;185:317-35.

41. Kacurakova M, Mathlouthi M. FTIR and laser-Raman spectra of oligosaccharides in water: characterization of the glycosidic bond. Carbohydr Res. 1996;284(2):145-57.

42. Petrou M, Edwards HGM, Janaway RC, Thompson GB, Wilson AS. Fourier-Transform Raman spectroscopic study of a Neolithic waterlogged wood assemblage. Anal Bioanal Chem. 2009;395(7):2131-8.
43. Durmaz S, Ozgenc O, Boyaci IH, Yildiz UC, Erisir E. Examination of the chemical changes in spruce wood degraded by brownrot fungi using FT-IR and FT-Raman spectroscopy. Vib Spectrosc. 2016;85:202-7.

44. Schrader B, Klump HH, Schenzel K, Schulz H. Nondestructive NIR FT Raman analysis of plants. J Mol Struct. 1999;509(1-3):201-12.

Publisher's Note Springer Nature remains neutral with regard to jurisdictional claims in published maps and institutional affiliations. 